\title{
The Effects of Heat Wave Temperature Patterns on Arabidopsis Thaliana
}

\author{
Sara Ramaiah ${ }^{\mathrm{a}}$, Patricia Talarczyk ${ }^{\mathrm{a}}$
}

Arabidopsis thaliana ecotype Col-0, a model organism in plant physiology, was studied in conjunction with heat wave temperature patterns, here defined as a multi-day pattern of oscillating high maximum daily temperatures and normal temperatures. The study was run with an experimental design, involving the construction of two plant growth chambers, of which one was set to maintain a constant temperature around $23^{\circ}$ Celsius. The other was set to vary in maximum temperature according to a heat wave definition based upon climate data from Columbia, Missouri, the native region of the studied ecotype of A. thaliana. Seeds were placed on fertilized soil and watered daily throughout the process of their growth, and they were moved into the growth chambers after sprouting under sunlight. Data was collected regarding each plant's developmental stage throughout plant growth, and biomass data was collected at the end of each individual's growth. Overall, an effect on the plants was found when the control and experimental groups were compared. The experimental group showed increased plant mortality and slowed plant development. This study has implications for the field of environmental science, climate research, and biology in that it may impact both the study of plant growth and planting seasons in agriculture. These results suggest potential for future studies into the genetic differences between plants that thrive under each set of conditions. These results are in agreement with other evidence of the negative effects of climate change on ecosystems.

\section{Introduction}

Scientists, politicians, and news sources alike discuss the impacts of climate change, but rarely do they talk about heat waves, and even more rarely do they talk about plants. The field of plant physiology, the discipline within botany concerned with plant functioning, features Arabidopsis thaliana (A. thaliana) heavily as a study organism, as its genome has been fully sequenced and it has a relatively simple, yet common, structure (Koornneef \& Meinke, 2005). Especially in relation to A. thaliana research, plant physiology has made recent advancements culminating in full genome sequencing in the 1990 Arabidopsis Genome Sequencing Project (Raikhel, 2001). Aside from A. thaliana, research using model organisms has great value and impact across scientific disciplines and practical applications alike. Although A. thaliana is the most common model organism, A. halleri and A. lyrata have their own merits, and A. thaliana is especially useful for its phylogenetic relationships to cultivated crops (Pitzschke, 2013). A. thaliana is the most prevalent model organism in plant physiology due to these factors, as well as its fast growth time and low space requirements (Pitzschke 2013; Koornneef \& Meinke 2005). This well-founded base in research is especially useful when considering the more modern phenomena of heat waves.

Modern heat waves in the United States have changed in nature when compared to historical data. Although heat waves as phenomena have occurred historically, they have increased in frequency by several measures across the country from 1979 to 2011 (Smith et al., 2013). Furthermore, heat waves are projected to become more prevalent in the future, especially in the central and midwestern plains and Great Lakes regions, which will be the first to demonstrate anthropogenic heat waves, or heat waves caused by human activity, with more prevalence than natural causes (Lindsey, 2018). These heat waves have grave implications for the population, as heat waves are linked with increased mortality rates, as studied within United States cities (Anderson and Bell, 2010). Beyond human populations, severe heat events have widespread negative effects on plant populations, as leaf temperature can often surpass air temperature, which can denature proteins (Wiebold, 2012). The prediction for an increase in heat wave prevalence and severity is thus important to consider both for populations and agriculture, as crop production and yield is greatly impacted by environmental temperature and extreme heat events (Wiebold, 2012). Future heat waves are projected to increase in intensity, primarily due to anthropogenic causes (Lopez et al., 2018). Furthermore, these anthropogenic causes are expected to overtake natural variation between the 2020s and 2070s, based upon region (Lopez et al., 2018). Because anthropogenic influences will be driving the prevalence of heat waves in the near future, finding what this will entail is imperative.

Plants, accounting for a great mass of life on Earth, will be a prime subject to the consequences of these increased heat waves. Given that all organisms respond to stimuli, it logically follows that plants have a biological mechanism that responds to a heat wave event. This mechanism, in the context of diurnal, or day-night, temperature fluctuations, is moderated by both the compounds TOC1 and PIF4, two complex macromolecule biological factors, in regards to time and temperature, respectively (Zhu et al., 2016). This being stated, there are certainly detriments to A. thaliana being exposed to high temperature extremes. A. thaliana, like most plants, follows a process of cellular respiration that is most effective at lower temperatures, named $\mathrm{C}_{3}$ for its use of a 3-carbon chain intermediary compound (Peterhansel et al., 2010). At higher temperatures, however, a key enzyme within this process binds to oxygen, starting a reaction cascade that releases carbon dioxide back into the environment, thereby not gaining energy (Peterhansel et al., 2010). This is likely the reason behind A. thaliana's measures of adapting to higher temperatures, which are essential to survival under extreme heat events.

Evidently, as shown by multiple studies, heat waves are a weather phenomenon that are occurring with more frequency in recent times, and are projected to continue this trend in the future (IPCC, 2014; Lopez et al., 2018; Smith et al., 2013). In this way, historical data in comparison with current data is extremely useful for analyzing climate trends and, more specifically, heat waves. Historical data on climate and weather has been extensively compiled by the National Oceanic and Atmospheric Administration (NOAA), as well as the sub-organization, the National Weather Service (NWS). Other databases are widely available as well, such as the North American Land Data Assimilation System (NLDAS-2), which is used to illustrate trends in heat wave prevalence 
regionally in the United States under several different models of heat waves (Smith et al., 2013). NOAA, as well, has performed analyses of climate trends that were published alongside their data (NOAA, 2018). For a larger scope than North America, the Intergovernmental Panel on Climate Change (IPCC), publishes intermittent in-depth reports of scientific knowledge and projections regarding all of the facets of climate change, including heat waves (IPCC, 2014). Although all of these publications are from diverse sources-an independent group, a sector of the federal government, and an international panel-several factors are common between them. One factor is particularly important: not only have heat waves increased in both scope and severity in recent years (Smith et al., 2013), but they are also projected to continue these trends (NOAA, 2018; IPCC, 2014). Predictions for the future of heat waves, though often similar, are not identical between climate models. Within the IPCC's publications, for example, several models of potential future trends are examined thoroughly, each accounting for different scopes of action on humanity's part in relation to climate change (IPCC, 2014). Any increase in the frequency or severity of heat waves will most likely have grave impacts on humanity, beyond direct potential for raised mortality (Anderson \& Bell, 2010) or increased sea levels (IPCC, 2014). Given that current projections point to such dire increases, one must consider the impact on society as a whole.

Agriculture is the foundation for human society, at least in part. If heat waves dramatically increase in scope and severity, then the crop plants relied on by most of the world will take a toll. Being closely related to many cultivated species, A. thaliana is an ideal plant to use for research into how such plants will be affected (Pitzschke, 2013). Likewise, because the internal biochemistry among $\mathrm{C}_{3}$ plants is similar in regards to photorespiration (Peterhansel et al., 2010), A. thaliana will likely respond in a manner that is applicable in scope to most $\mathrm{C}_{3}$ plants. Within the current body of knowledge, one main factor regarding temperature and plant physiology is apparent: The contrast in effects on A. thaliana for multiple-day-long heat waves and constantly elevated temperature. Although A. thaliana's response to diurnal temperature fluctuations is well known (Zhu et al., 2016), there is ostensibly no research contrasting the physiological responses from heat wave events and constantly elevated temperature. Heat wave events, as compiled by Smith and her colleagues, are well documented in observational literature but are not well studied in an experimental nature alongside a steady temperature higher than the mean. Likewise, the measures for a plant's growth in terms of biomass, and development time an individual takes to reach a particular growth stage, have not been used as measures of study for this setup, and should provide both great insight into the potential implications of findings into agriculture, as well as good foundations for comparison to a wider body of knowledge. These considerations lead to the central research question for this study, "How do oscillating patterns of high temperature extremes impact biomass and development stages in A. thaliana?" Based on research into the current body of knowledge on plant physiology and environmental science, I hypothesized that heat wave temperature patterns would slow down the development of $A$. thaliana and reduce overall biomass.

\section{Experimental Procedures}

Overall, the method employed was an experimental study design involving randomizing participants, assigning treatment groups to each, and tracking results. This was determined as the most optimal study design to research causative information. If an effect is found, such evidence supports a conclusion of a causative relationship. Determining a causative relationship between the presence of heat waves and growth in A. thaliana will most effectively contribute to the body of knowledge regarding information about heat waves vs. constant temperatures.

Columbia ecotype A. thaliana, or Col-0 seeds were used in this study, as they are a natural accession of A. thaliana found in the continental United States, and were also used by Boyes and associates for growth stage research (Boyes et al., 2001). Furthermore, this ecotype of $A$. thaliana thrives within the area of Columbia Missouri, which is predicted to be a particularly vulnerable region to future heat waves (Lindsey, 2018). The seeds were planted on potting soil, and following the guidelines from the Arabidopsis Biological Resource Center (ABRC) at the Ohio State University, were planted using a 14-14-14 (percents nitrogen, phosphate, and potassium, respectively) slow release fertilizer in potting soil in two 72-cell plant trays with clear plastic covers (Seed Handling, 2018). After planting, the seeds were allowed to sprout until they reached approximately 1.5 centimeters in height, which took roughly two weeks, when they were moved into two treatment groups via clustered random sampling. Plants in Group 1 received 24 hours of light, and were kept at an average temperature of 23 degrees Celsius, in accordance with recommendations from the ABRC (Seed Handling, 2018). Group 2 was temperature controlled to exhibit heat wave behavior as defined by Meehl and Tebaldi and based upon climate data from Columbia, Missouri (Meehl \& Tebaldi, 2004; Climate, 2019). The definition set forth is that for a heat wave, with T1 (temperature 1) defined as the 97.5th percentile of temperature conditions and T2 (temperature 2) as the 81st percentile, the heat wave is the longest number of consecutive days with a daily maximum temperature above $\mathrm{T} 1$ for at least 3 days, the average daily maximum must be above $\mathrm{T} 1$, and the daily maximum must be above $\mathrm{T} 2$ for all days (Meehl \& Tebaldi, 2004). Refer to Table 1 for a breakdown of temperature conditions in each box. In order to successfully mimic the maximum daily temperatures defined by Meehl and Tebaldi, the heater used within the experimental growth chamber construction was set with a timer to the desired temperature for a period of between 4 and 6 hours, at which time it would turn off and air circulation throughout the room would bring the temperature back to approximately the ambient room temperature. The plants were expected to grow for a total of seven weeks from planting until the end of flower production (Boyes et al., 2001). At the end of the growing period, the plants were unearthed, rinsed, and allowed to air dry on a paper towel. They were then transported to my high school, where their mass was recorded in grams with a sensitive electronic balance. 
Table 1 Temperature Treatments for Each Group

Days after transfer
Box 1: Control temperature $\left({ }^{\circ} \mathrm{C}\right)$
Box 2: Heat wave Max. Temp. $\left({ }^{\circ} \mathrm{C}\right)$

\begin{tabular}{ccc}
\hline $1-6$ & 23.0 & 23.0 \\
$7-9$ & 23.0 & 26.7 \\
$10-12$ & 23.0 & 28.9 \\
$13-14$ & 23.0 & 26.7 \\
$15-22$ & 23.0 & 23.0 \\
$23-24$ & 23.0 & 26.7 \\
$25-29$ & 23.0 & 28.9 \\
$30-31$ & 23.0 & 26.7 \\
$32-42$ & 23.0 & 23.0 \\
\hline
\end{tabular}

The growth chambers used for treatment groups were constructed with materials found in Table 2. The growth chamber was designed in reference to that of Katagiri and his research team in terms of critical design elements, but was modified due to budgetary and spatial limitations for this study (Katagiri et al., 2015). The PVC frame was first fitted together with 3-way elbow joints, then oriented to have the longer edges parallel to the floor. Mylar reflective insulation was then trimmed to size and secured to each of the larger (3' by 2') faces and one of the smaller (2' by 2') faces, using duct tape to seal the edges. Rigid pink foam board insulation was then adhered to the exterior of the Mylar insulation on the larger sides. To secure the fluorescent lights, wood screws were used with mounts on the light ballasts to attach to a reinforcing plank along the top of the box. A LabQuest 1 with three Vernier temperature probes was used for the setup to monitor temperature in the middle of the control chamber, the experimental chamber, and the ambient room temperature. During setup, one of the square sides of the box was covered with Mylar insulation that was removable to allow for plant care. One of the final growth chambers after construction is shown in Figure 1. For more information about the products used and additional pictures of construction, refer to Appendix A. This construction was used for each setup in the study.

Table 2 Material s Used

\begin{tabular}{|c|c|}
\hline Material Type & Quantity \\
\hline \multicolumn{2}{|c|}{ Framing and Support Materials } \\
\hline $3 / 4$ in. PVC tubing $-3 \mathrm{ft}$. long & 8 \\
\hline $3 / 4$ in. PVC tubing $-2 \mathrm{ft}$. long & 16 \\
\hline $3 / 4$ in. PVC 3 -way elbow joint & 16 \\
\hline Common board plank - 39 in. & 2 \\
\hline \multicolumn{2}{|c|}{ Insulation Materials } \\
\hline 2 -sided reflective mylar insul ation & 28 feet \\
\hline $1 / 2$ " thick rigid pink foam board insulation - 4'x 8 ' sheet & 2 sheets \\
\hline \multicolumn{2}{|c|}{ Electrical, Heating, and Lighting } \\
\hline Temperature-control led personal heater & 2 \\
\hline 18" T8 Grow Light fluorescent bulb & 4 \\
\hline $18 " \mathrm{~T} 8$ fluorescent ballast & 4 \\
\hline Extension cords & 2 \\
\hline \multicolumn{2}{|c|}{ Miscellaneous Uses } \\
\hline Duct tape & 1 roll \\
\hline LabQuest 1 & 1 \\
\hline Vernier temperature probe & 3 \\
\hline
\end{tabular}




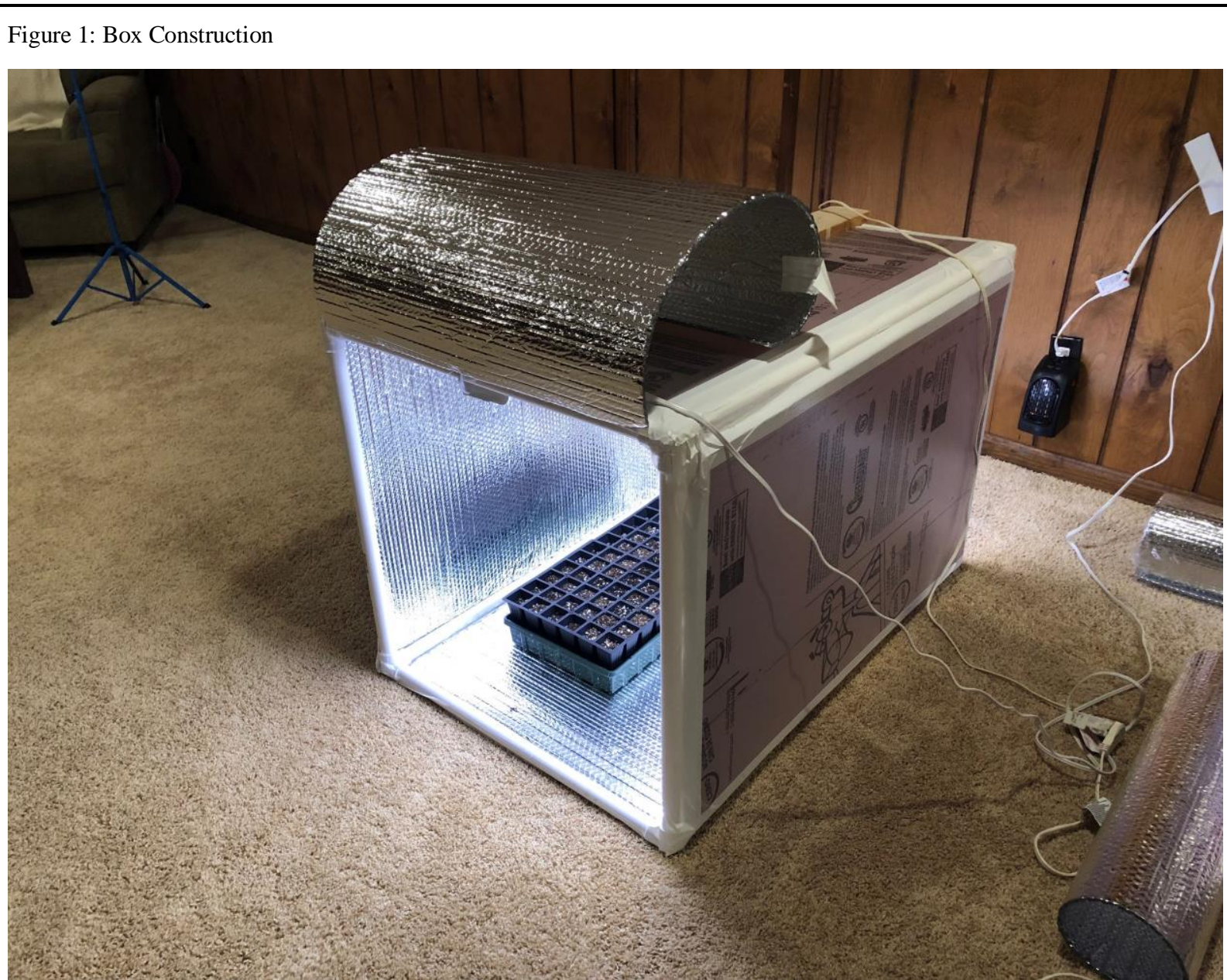

The independent variable for this study was the treatment group in which the plants were placed. The dependent variables measured were stages of development in the plants and plant biomass. The developmental stages measured in this study are the same as those defined by a 2001 study on the phenotypic analysis of $A$. thaliana based on growth stages (Boyes et al., 2001). These definitions break down the life cycle of $A$. thaliana into principal growth stages $1,3,5,6,8$, and 9, and then further into substages, which are shown in Table 3. Plants in this study were examined daily to determine the most appropriate stage of growth to define them, as well as any auxiliary information. Biomass was measured in metric grams using an electronic balance after the plant specimens completed principal growth stage 6.

Table 3 Excerpt from "Table 2: Arabidopsis Growth Stages for the Soil-Based Phenotypic Analysis Platform” (Boyes et al. 2001)

\begin{tabular}{lr} 
Stage & Description \\
\hline Principal Growth Stage 1 & Leaf Development \\
1.02 & 2 rosette leaves $>1 \mathrm{~mm}$ in length \\
1.03 & 3 rosette leaves $>1 \mathrm{~mm}$ in length \\
1.04 & 4 rosette leaves $>1 \mathrm{~mm}$ in length \\
1.05 & 5 rosette leaves $>1 \mathrm{~mm}$ in length \\
1.06 & 6 rosette leaves $>1 \mathrm{~mm}$ in length \\
1.07 & 7 rosette leaves $>1 \mathrm{~mm}$ in length \\
1.08 & 8 rosette leaves $>1 \mathrm{~mm}$ in length \\
1.09 & 9 rosette leaves $>1 \mathrm{~mm}$ in length
\end{tabular}




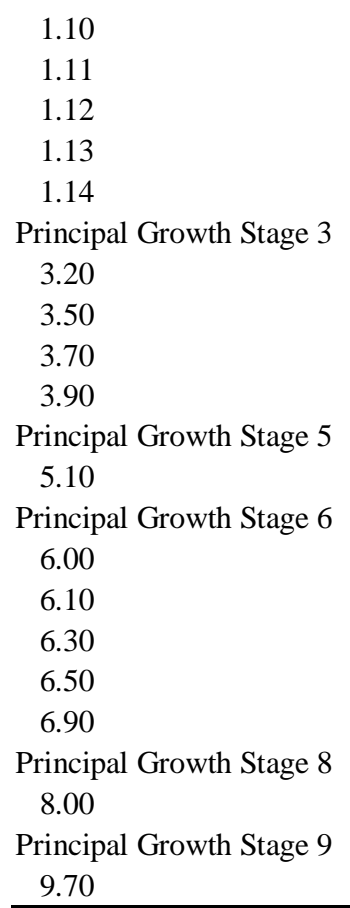

1.10

1.11

1.12

1.13

1.14

Principal Growth Stage 3

3.20

3.50

3.70

3.90

Principal Growth Stage 5

5.10

Principal Growth Stage 6

6.00

6.10

6.30

6.50

6.90

Principal Growth Stage 8 8.00

Principal Growth Stage 9 9.70

\author{
10 rosette leaves $>1 \mathrm{~mm}$ in length \\ 11 rosette leaves $>1 \mathrm{~mm}$ in length \\ 12 rosette leaves $>1 \mathrm{~mm}$ in length \\ 13 rosette leaves $>1 \mathrm{~mm}$ in length \\ 14 rosette leaves $>1 \mathrm{~mm}$ in length \\ Rosette Growth \\ Rosette is $20 \%$ of final size \\ Rosette is $50 \%$ of final size \\ Rosette is $70 \%$ of final size \\ Rosette growth complete \\ Inflorescence emergence \\ First flower buds visible \\ Flower Production \\ First flower open \\ $10 \%$ of flowers to be produced have opened \\ $10 \%$ of flowers to be produced have opened \\ $10 \%$ of flowers to be produced have opened \\ Flowering complete \\ Silique ripening \\ First silique shattered \\ Senescence \\ Senescence complete; ready for seed harvest
}

As a randomized controlled trial design, there were many controls, independent, and dependent variables. The independent variable, or explanatory variable, used in this study was the temperature conditions that the plants were subjected to. The dependent variables, or response variables, were the biomass of each plant and the development times of the plants. I aimed to control for the watering, soil nutrients, and light that each plant was exposed to. There are potential extraneous variables with this study, such as humidity differences and potential seed defects from any one stock provided. These extraneous variables were minimized at all times throughout the course of the study, both by the use of control standard conditions for each group and through the use of clustered random sampling of the seed sprouts before transfer into the growth chambers. Because of this minimization, extraneous variables are likely not a limitation of the study.

\section{Results}

The data collected over the course of the study regarding developmental stages is shown below. Data for the control group is listed in Table 4, and data for the experimental group is shown in Table 5. Each of these tables shows data for the plants that survived the course of the study. Table 6 shows summary data for plants that did not survive the course of the study for both the control and experimental groups. The date of death was observed as the day after the individual plant was last seen alive. The data was separated for plants that lived and died so as to better analyze the differences in each subgroup between the experimental conditions. For a complete spreadsheet of all data for the plants in the control group, see Appendix B. For a complete spreadsheet of all data for the plants in the experimental group, see Appendix C.

Data on Growth Stages and Plant Development

Table 4: Control, Survived

Stages of Leaf Development

\begin{tabular}{llllllll}
1.04 & 1.05 & 1.06 & 1.07 & 1.08 & 1.09 & 1.1 & 1.11 \\
\hline
\end{tabular}

Plant No.

Date (after sowing) growth stage was reached

$\begin{array}{lllllllll}13 & 14 & 20 & 22 & 27 & 29 & 32 & & \\ 14 & 25 & 29 & 33 & 37 & 38 & 47 & & \\ 16 & 15 & 23 & 26 & 30 & 32 & 37 & 48 \\ 17 & 17 & 25 & 28 & 31 & 34 & 37 & 40\end{array}$




\begin{tabular}{llllllll}
18 & 17 & 24 & 26 & 30 & 33 & 35 & 39 \\
19 & 18 & 25 & 27 & 30 & 33 & 35 & 40 \\
20 & 17 & 26 & 29 & 33 & 35 & & \\
23 & 28 & 36 & 38 & 39 & 40 & 45 & \\
24 & 16 & 23 & 26 & 29 & 32 & 35 & \\
25 & 15 & 23 & 26 & 30 & 33 & & \\
28 & 15 & 23 & 26 & 29 & 31 & & \\
29 & 17 & 25 & 27 & 30 & 33 & 39 & 48 \\
\hline
\end{tabular}

Table 5: Experimental, Survived

Stages of Leaf Development

1.04

1.05

1.06

1.07

1.08

1.09

1.1

1.11

Plant No.

6

9

10

11

14

18

32

35

41

Date (after sowing) growth stage was reached

\begin{tabular}{llllllll}
19 & 27 & 30 & 31 & 35 & 39 & 42 & 43 \\
17 & 25 & 28 & 31 & 34 & 36 & & \\
19 & 30 & 33 & 37 & 40 & 42 & 46 & 49 \\
19 & 40 & 46 & & & & & \\
18 & 30 & 31 & 33 & 36 & 39 & 41 & 44 \\
15 & 19 & 22 & 30 & 32 & 42 & 46 & \\
40 & 43 & 46 & & & & & \\
19 & 28 & 30 & 32 & 36 & 37 & & \\
27 & 40 & 42 & 47 & & & & \\
\hline
\end{tabular}

Table 6: Summary Data for Date of Death

\begin{tabular}{lccc} 
& $N$ (number in sample) & mean & S (standard deviation) \\
Control Group & 35 & 23.20 & 6.282 \\
Experimental Group & 33 & 21.06 & 2.633 \\
\hline
\end{tabular}

Overall, out of the 47 initial sprouts in the control group, 12 plants survived until the completion of the study. Of the 42 initial sprouts in the experimental group, 9 plants survived until the completion of the study. Summary data displaying the temperature and average number of leaves for the experimental group can be found in Table 7, and a graph of the average number of leaves and the temperature versus time can be found in Figure 2.

Summary Data for Experimental Group

Table 7: Experimental Group Summary

\begin{tabular}{ccc} 
Day & Temperature & Average Number of Leaves \\
\hline 1 & 23 & 3.2 \\
2 & 23 & 3.4 \\
3 & 23 & 3.4 \\
4 & 23 & 4 \\
5 & 23 & 4
\end{tabular}


7. Journal of Student Research

AP Research (2019)

\begin{tabular}{|c|c|c|}
\hline 6 & 23 & 4 \\
\hline 7 & 26.7 & 4 \\
\hline 8 & 26.7 & 4 \\
\hline 9 & 26.7 & 4 \\
\hline 10 & 28 & 4.3 \\
\hline 11 & 28 & 4.5 \\
\hline 12 & 28 & 4.6 \\
\hline 13 & 26.7 & 5 \\
\hline 14 & 26.7 & 5 \\
\hline 15 & 23 & 5.4 \\
\hline 16 & 23 & 5.9 \\
\hline 17 & 23 & 6.1 \\
\hline 18 & 23 & 6.4 \\
\hline 19 & 23 & \\
\hline 20 & 23 & 7.5 \\
\hline 21 & 23 & 7.8 \\
\hline 22 & 23 & 7.1 \\
\hline 23 & 26.7 & 6.8 \\
\hline 24 & 26.7 & 7.1 \\
\hline 25 & 28 & 7.5 \\
\hline 26 & 28 & 7.6 \\
\hline 27 & 28 & 8.2 \\
\hline 28 & 28 & 8.3 \\
\hline 29 & 28 & 8.4 \\
\hline 30 & 26.7 & 8.4 \\
\hline 31 & 26.7 & 9.1 \\
\hline 32 & 23 & 9.3 \\
\hline 33 & 23 & 9.4 \\
\hline 34 & 23 & 9.6 \\
\hline
\end{tabular}

Figure 2: Temperature and Leaves vs. time (Days since start of study)

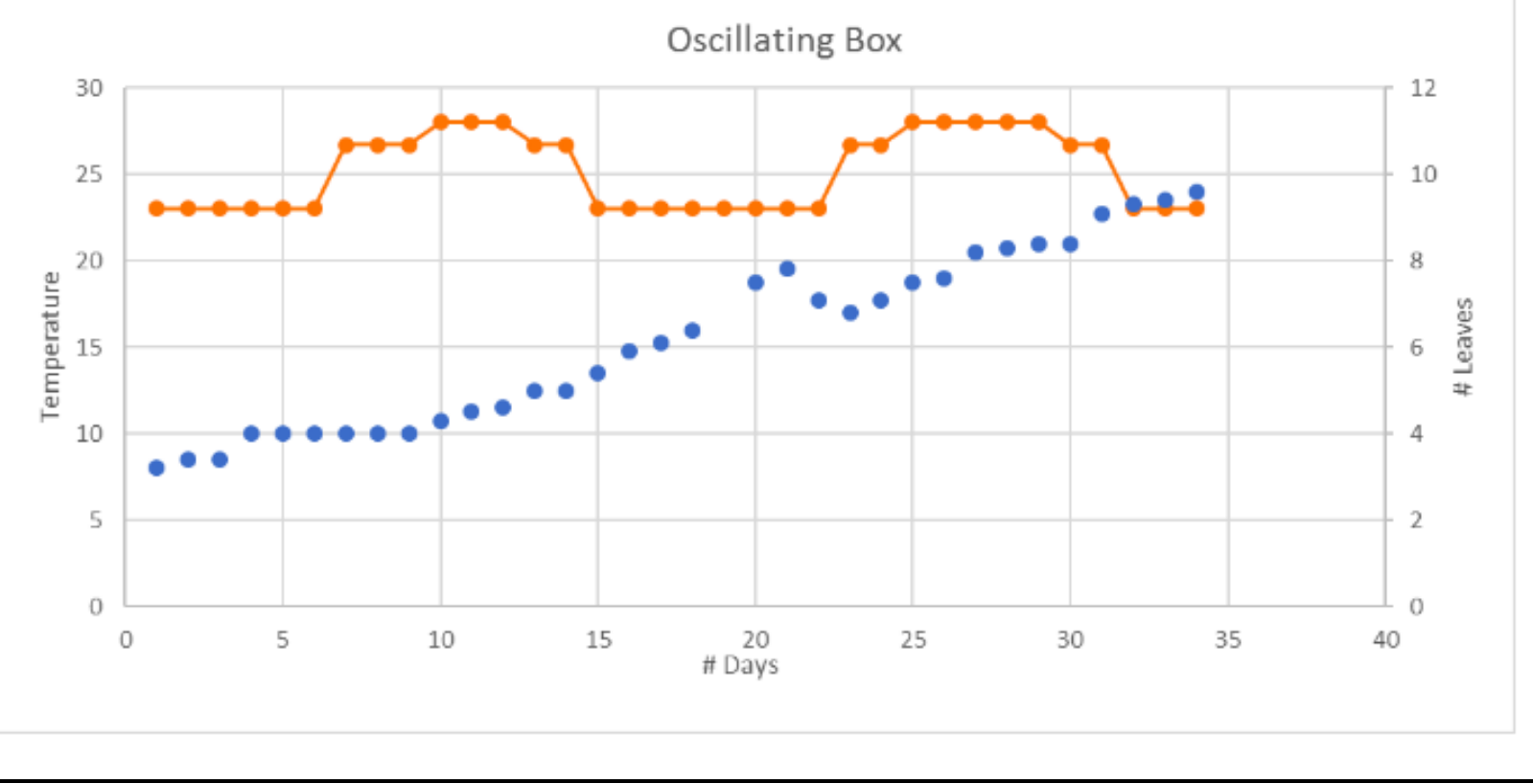


The above figures and tables display the data in terms of when temperature treatments began, rather than days since sprouting, as days since sprouting was used only for comparison to the control group. This data was expressed beginning from the treatment so that an ANOVA could be run on the experimental data. There is a data point missing from day 19 (34 days from sprouting) because I was unable to collect any data that night.

\section{Data on Biomass}

After the study was completed, data was collected regarding the biomass of all plants that survived until the end of the study. This data is presented in Table 8 below, for both the control and experimental groups.

Table 8: Biomass Data

\begin{tabular}{|c|c|c|c|}
\hline \multicolumn{2}{|c|}{ Control Plants } & \multicolumn{2}{|c|}{ Experimental Plants } \\
\hline & Biomass & & Biomass \\
\hline Plant No. ${ }^{\mathrm{a}}$ & & Plant No. ${ }^{\mathrm{a}}$ & \\
\hline 1 & 0.021 & 1 & 0.166 \\
\hline 2 & 0.044 & 2 & 0.074 \\
\hline 3 & 0.054 & 3 & 0.086 \\
\hline 4 & 0.038 & 4 & 0.009 \\
\hline 5 & 0.019 & 5 & 0.002 \\
\hline 6 & 0.023 & 6 & 0.009 \\
\hline 7 & 0.027 & 7 & 0.089 \\
\hline 8 & 0.052 & 8 & 0.052 \\
\hline 9 & 0.041 & 9 & 0.021 \\
\hline 10 & 0.023 & & \\
\hline 11 & 0.038 & & \\
\hline 12 & 0.013 & & \\
\hline
\end{tabular}

a: Plant number in this context is unrelated to the previous data, as plants could not be positively identified once transported to the weighing area.

\section{Data Analysis}

Multiple data analyses were run upon different sets of data. For the plant mortality, a chi squared contingency table was performed upon data, yielding no statistical significance. For both the time of plant death and overall biomass, a t-test was performed, each reaching statistical significance at $\mathrm{p}<0.10$. For the influence of temperature on leaf development, an ANOVA was run on the experimental data, finding a significant negative association between temperature and leaf development. Finally, regressions of both the control and experimental groups were ran, showing a difference in leaf development between the two. I used Social Science Statistics online calculators for both the chi-squared test and the t-tests (2019), and I used MiniTab statistical software to compute my ANOVA (Ryan et al., 1989).

Figure 3 shows the readout from a chi square $2 \times 2$ contingency table regarding plant mortality rates between the control and experimental groups. The data shows that there was a small increase in mortality from the control to the experimental groups, but with a p-value of 0.649011 , the difference in mortality between the two groups is not statistically significant. 
Figure 3: Chi squared Contingency Table

\begin{tabular}{|l|l|l|l|l|}
\hline & Survived & Died & Marginal Row Totals \\
\hline Control & $12(11.09)[0.07]$ & $35(35.91)[0.02]$ & 47 \\
\hline Experimental & $9(9.91)[0.08]$ & $33(32.09)[0.03]$ & 42 \\
\hline Marginal Column Totals & 21 & 68 & 89 (Grand Total) \\
\hline
\end{tabular}

The chi-square statistic is 0.2071 . The $p$-value is .649011 . This result is not significant at $p<.10$.

The chi-square statistic with Yates correction is 0.0421 . The $p$-value is .8375 . Not significant at $p<.10$.

Figure 4 shows the readout from a t-test difference of means for the time of death between the control group and the experimental group. Of the plants that died in treatment 2, the experimental group, plants died earlier than plants in treatment 1 , the control group. In other words, plants experiencing heat wave temperature patterns died more quickly than plants experiencing control conditions. The $\mathrm{p}$ value for this test is 0.037302 for a $\mathrm{t}$ score of 1.81156 , which is significant at $\mathrm{p}<0.05$.

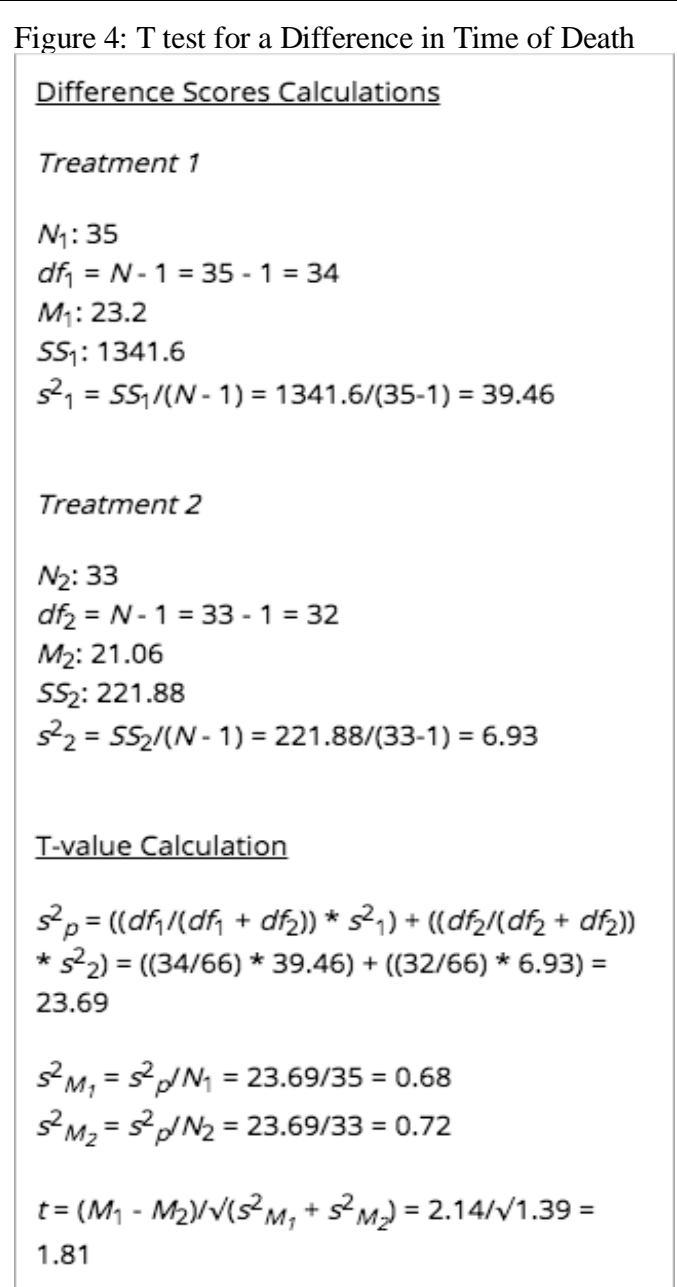


To determine if a t test would be appropriate for assessing a difference in biomass, a normal plot was run on the biomass data for both the control and experimental groups, which is shown in Figure 5. After it was determined to be a roughly normal distribution for both data sets, with $r$ values over 0.9 for each, a t test for a difference in means was run. The readout from this test is shown in Figure 6. With a p value of 0.077449 on a t score of -1.48139 , biomass among the experimental plants was higher at $\mathrm{p}<0.10$.

Figure 5: Normal plots for biomass, Control plants (top) and experimental plants (bottom)

\section{Normal Probability Plot: Control Data}

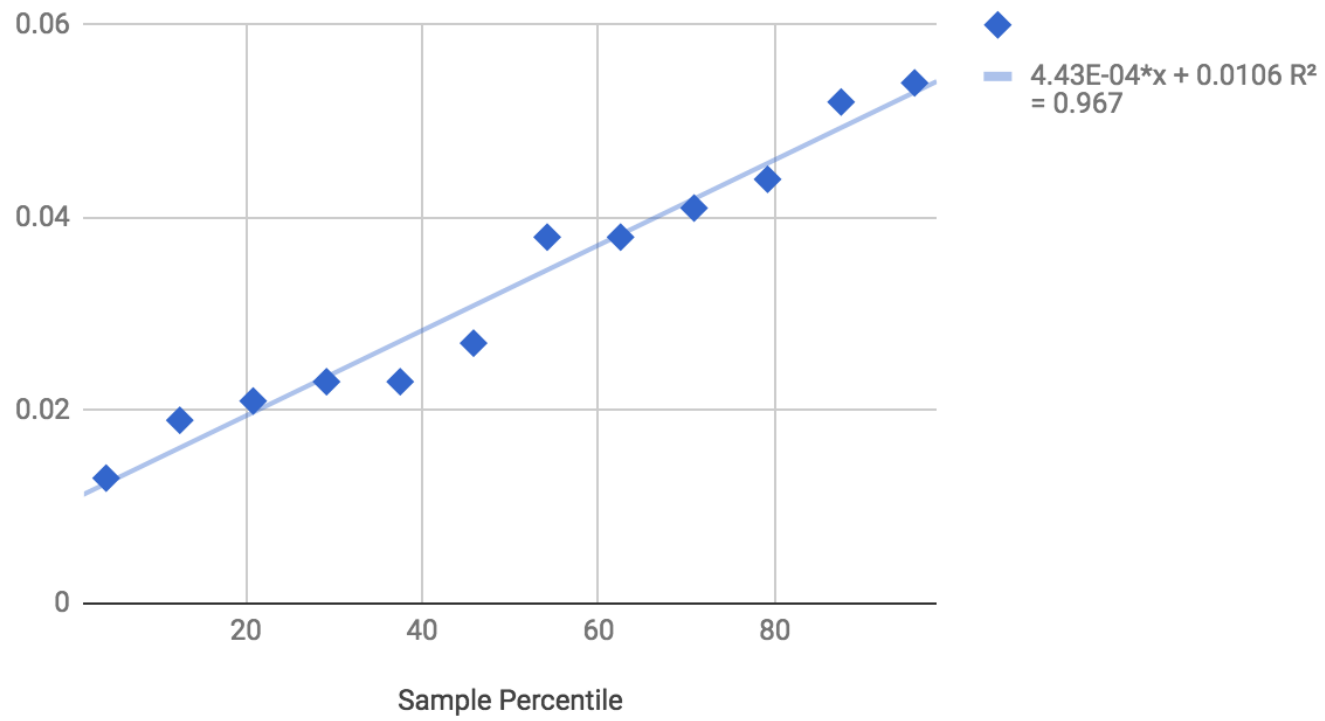

\section{Normal Probability Plot: Experimental Data}

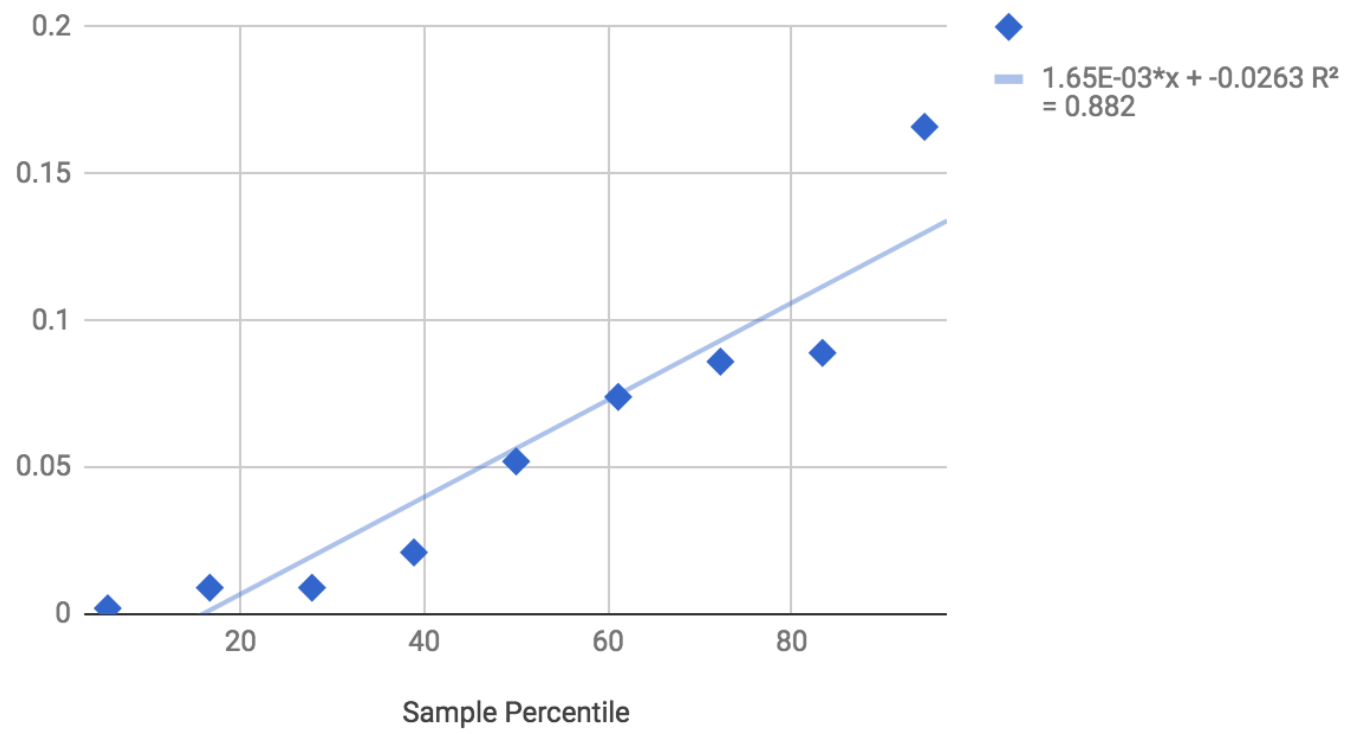


Figure 6: T test for a difference in biomass

Difference Scores Calculations

Treatment 1

$N_{1}: 12$

$d f_{1}=N-1=12-1=11$

$M_{1}: 0.03$

$S S_{1}: 0$

$s^{2}{ }_{1}=S S_{1} /(N-1)=0 /(12-1)=0$

\section{Treatment 2}

$N_{2}: 9$

$d f_{2}=N-1=9-1=8$

$M_{2}: 0.06$

$S S_{2}: 0.02$

$s^{2}{ }_{2}=S S_{2} /(N-1)=0.02 /(9-1)=0$

\section{$\underline{\text { T-value Calculation }}$}

$s_{p}^{2}=\left(\left(d f_{1} /\left(d f_{1}+d f_{2}\right)\right) * s^{2}{ }_{1}\right)+\left(\left(d f_{2} /\left(d f_{2}+d f_{2}\right)\right)\right.$

$\left.* s^{2} 2\right)=((11 / 19) * 0)+((8 / 19) * 0)=0$

$s^{2} M_{1}=s^{2} p / N_{1}=0 / 12=0$

$s^{2} M_{2}=s^{2} p / N_{2}=0 / 9=0$

$t=\left(M_{1}-M_{2}\right) / \sqrt{ }\left(s^{2} M_{1}+s^{2} M_{2}\right)=-0.02 / \sqrt{ } 0=-1.48$

Regarding the experimental data, an ANOVA was run on the average number of leaves over time in connection with the explanatory variables of time passed and temperature, shown in Figure 7. This ANOVA found a statistically significant effect of temperature on leaf development, with a $\mathrm{p}$ value of less than 0.0001 . This low p value indicates that there is a less than a $0.01 \%$ chance that the data could occur by random chance. This ANOVA modeled linear interaction between the effects of temperature and time, which was also significant at $\mathrm{p}<0.10$ with a $\mathrm{p}$ value of 0.0591 . This ANOVA presents a linear model in which the number of leaves on an individual plant can be predicted with reasonable accuracy by the equation Leaves $=7.28127-0.11831 *$ Temperature $+0.097721 *$ Days +4.32430E-003 Days*Temperature. 
Figure 7: ANOVA on Experimental Data

ANOVA for Response Surface 2FI model

Analysis of variance table [Partial sum of squares - Type III]

Sum of Mean $F$ p-value

Source Squares df Square Value Prob $>$ F

Model $\quad 132.19 \quad 3 \quad 44.06 \quad 641.92<0.0001$ significant

A-Temperature $\quad 1.93 \quad 1 \quad 1.93 \quad 28.13<0.0001$

B-Days $\quad 117.68 \quad 1 \quad 117.681714 .34<0.0001$

$\begin{array}{lllllll}A B & 0.26 & 1 & 0.26 & 3.86 & 0.0591\end{array}$

Residual $\quad 1.9929 \quad 0.069$

Cor Total $\quad 134.1832$

Std. Dev. $\quad 0.26$ R-Squared $\quad 0.9852$

Mean 6.16 Adj R-Squared 0.9836

C.V. \% 4.25 Pred R-Squared 0.9823

PRESS 2.38 Adea Precision 71.336

-2 Log Likelihood 0.98 BIC 14.97

AICE $\quad 10.41$

Final Equation in Terms of Actual Factors:

\# Leaves $=$

$+7.28127$

$-0.18831 *$ Temperature

$+0.097721 *$ Days

$+4.32430 \mathrm{E}-003 *$ Temperature * Days

Finally, regressions of the control group and the experimental group were placed side by side, then offset to clearly show a difference in slope, which is shown in Figure 8. The slope of the regression line for the control data is larger, which suggests that between the two groups, the control group had an overall faster development. 
Figure 8: Comparison of regressions

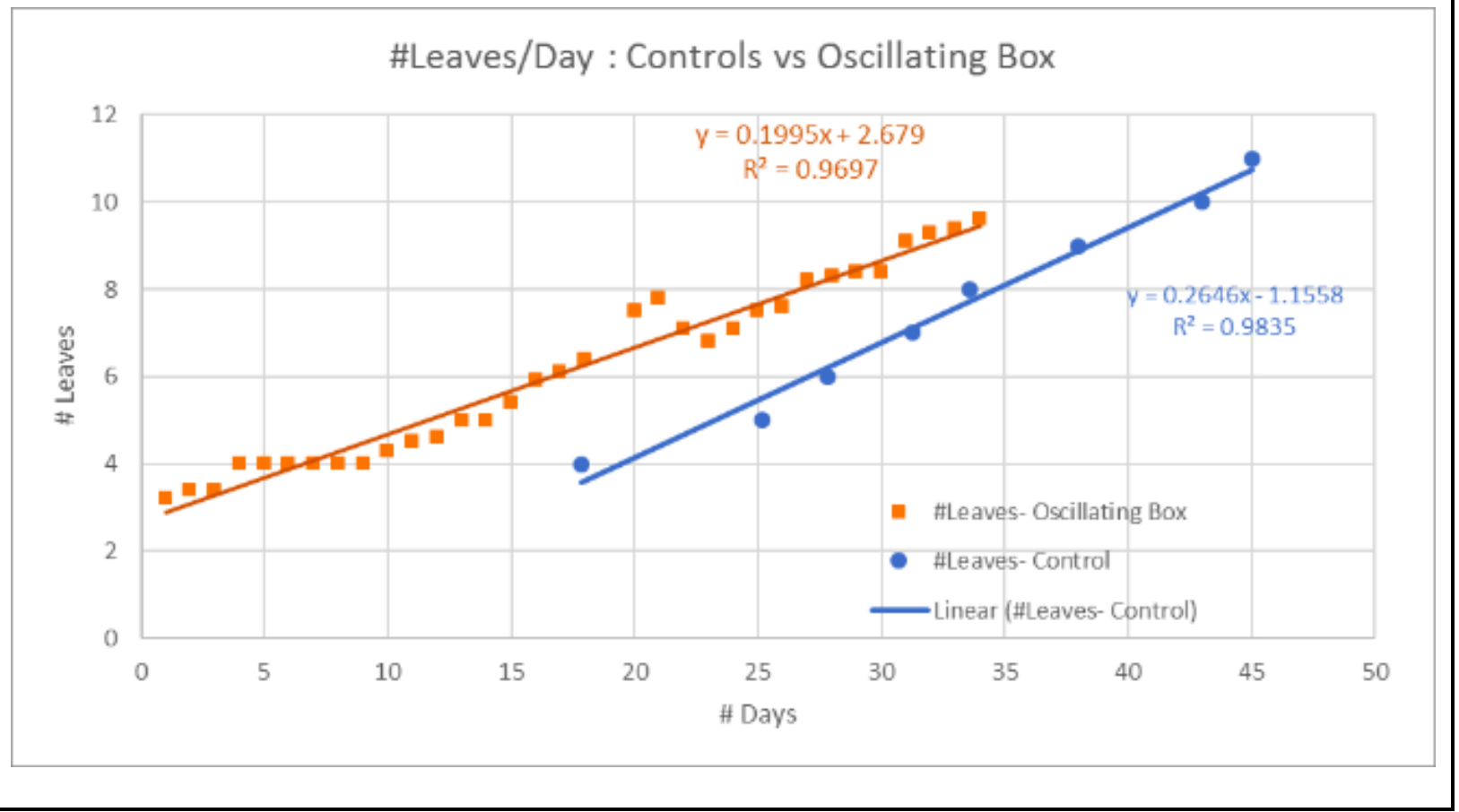

This wide array of data analysis overall supports the hypothesis that heat wave temperature patterns slow down or otherwise hinder the development of $A$. thaliana. There was a small difference in mortality between the two groups, but it was not statistically significant. This difference may have been random chance, but there is potential that there was an influence from the heat wave temperature conditions. In regards to time of death, however, the difference was significant, which is an unexpected addition to the effects of heat wave temperatures that was not hypothesized. This data, in conjunction with the ANOVA that demonstrates a negative effect of temperature, suggests that heat wave temperatures slow down development in A. thaliana, in addition to accelerating the rate of death. Contrary to my hypothesis, however, this study found that the biomass among A. thaliana was significantly higher among the experimental group and the control group, which seems to contrast the significant reduction in development. This unexpected outcome is potentially a consequence of the small number of data points in this study, but suggests that there may be an overall trend of larger biomasses for plants exposed to heat wave temperature patterns.

This study had several limitations that affect the data analyzed within this paper. First and foremost, this study was conducted independently in a home environment without the access to precise tools and resources that one would have in a lab environment. As such, there is a substantial chance of error on the part of the researcher that influenced the outcome of this study. These potential errors vary greatly, but the most prevalent potential source of error is within temperature adjustment and temperature measurement. The tools I had access to were not precise in the establishment of a temperature, even though there were temperature settings, largely due to their nature as a consumer product. Furthermore, the temperature probes I used were designed for taking temperature at one point, and thus did not account for air circulation or air temperatures, so there may have been error in measurement and regulation of temperature. A second limitation of this study is the use of store bought plant growth lights, which worked well enough to keep some plants alive, but were likely a cause of the widespread plant death throughout the study. This great quantity of plant death limited my ability to perform statistical tests or draw meaningful conclusions from the few plants still alive at the end of the study. Despite these limitations, the statistically significant evidence found through this study suggest widespread effects on plants due to heat wave temperatures.

\section{Discussion}

This study, despite limitations, has fairly wide-reaching implications. The statistically significant effect of heat waves upon A. thaliana as a model organism have the potential to impact other studies within plant physiology, in that more realistic simulations of climate change and elevated temperatures may need to factor in the presence of heat waves to be the most accurate to the real world. Considering the push for ever more accurate climate models and projections of the future, the statistically significant effects that heat waves have had on plants within this study alone indicate the need for more dedicated research into the specific effects that heat waves can have on the environment and on specific organisms. Within more generalized environmental science, a defi nite impact of heat waves upon this particular model organism may prompt the investigation of ecological impacts of heat waves given different tolerance levels of different organisms. From an agricultural perspective, this evidence that heat waves slow down plant 
development has the potential to impact growing seasons and crop optimization, given that many $\mathrm{C} 3$ organisms are as sensitive as A. thaliana or more to changes in temperature.

Given both this study's limitations and the further questions that arose over the course of the study, there are many possible directions for future research. Overall, more research should be done for similar research questions in a laboratory setting, where each variable and control (e.g. temperature, light, soil nutrients and moisture) can be more precisely manipulated than within a home setting. One possible related question is if there is a genetic difference between the plants that thrive under normal conditions and the plants that thrive under heat wave conditions. Throughout the course of the study, general observations of the plants in the experimental and control setups indicated that some plants thrived significantly more than similar plants under identical conditions, and that the same was true between both the control and experimental groups. Such a difference may be attributable to genetic variations that naturally exist amongst different individual organisms. This would be an interesting topic of research pertaining to the possibility of genetic engineering for temperature resistance, a very current field of research. Another possible avenue of future studies is to analyze historical data and experimental data for various crop plants to determine the level of resistance to heat wave temperature fluctuation as a means of drawing conclusions about variance between types of plants. Likewise, one could also study the internal mechanisms involved with non-diurnal temperature changes within various plants.

The evidence found within this study is in large part an extension of research found within the wider body of knowledge. The suggestion of a negative impact on plants based on temperature is in line with previous research and evidence on the negative effects of sustained heat on plants. Previous studies and reports suggest a variety of complicated factors at play, such as a denaturation of proteins and enzymes within leaves that causes a decrease in effectiveness (Wiebold, 2012). This study then extends that knowledge further by demonstrating specific negative effects of heat wave temperatures on plants, as opposed to a more generalized working definition of elevated temperatures. The great limitations of this study's efficacy reduce the amount of connections back to the current body of knowledge, although future research within a lab environment could lend more evidence and connections to the current body of knowledge regarding environmental science and plant physiology.

\section{Acknowledgements}

I would like to first thank the staff of the Arabidopsis Biological Resource Center at the Ohio State University, and specifically Julie Miller, a staff member. Ms. Miller assisted me in acquiring the Columbia ecotype of A. thaliana and directed me to information available online regarding $A$. thaliana and how to properly care for it. I would also like to acknowledge my AP Research teacher, Mrs. Talarczyk, who guided me in developing my project and gathering information and evidence to design a study. Mrs. Talarczyk was also an incredibly valuable resource when I applied to present my research at the Northeast Ohio Science and Engineering Fair. I would like to further acknowledge my parents, without whom I would have been unable to conduct this study at all, given their help with purchasing materials and constructing the device setups. The funding for this study came entirely from myself and my parents. Because of the independent nature of this study, there are no apparent possible conflicts of interest present.

\section{References}

Anderson, G. B., \& Bell, M. L. (2011). Heat Waves in the United States: Mortality Risk during Heat Waves and Effect Modification by Heat Wave Characteristics in 43 U.S. Communities. Environmental Health Perspectives, 119(2), $210-218$. doi:10.1289/ehp.1002313

Boyes, D. C., Zayed, A. M., Ascenzi, R., McCaskill, A. J., Hoffman, N. E., Davis, K. R., \& Görlach, J. (2001). Growth stagebased phenotypic analysis of Arabidopsis: a model for high throughput functional genomics in plants. The Plant cell, 13(7), 1499-1510. doi:10.1105/tpc.010011

Climate Colombia - Missouri. (2019). Retrieved January 10, 2019, from https://www.usclimatedata.com/climate/columbia/missouri/united-states/usmo0193

Climate Monitoring. (n.d.). Retrieved October 15, 2018, from https://www.ncdc.noaa.gov/climate-monitoring/

IPCC, 2014: Climate Change 2014: Synthesis Report. Contribution of Working Groups I, II and III to the Fifth Assessment Report of the Intergovernmental Panel on Climate Change [Core Writing Team, R.K. Pachauri and L.A. Meyer (eds.)]. IPCC, Geneva, Switzerland, 151 pp.

Katagiri, F., Canelon-Suarez, D., Griffin, K., Petersen, J., Meyer, R. K., Siegle, M., \& Mase, K. (2015). Design and Construction of an Inexpensive Homemade Plant Growth Chamber. Plos One,10(5). doi:10.1371/journal.pone.0126826

Koornneef, M., \& Meinke, D. (2010). The Development of Arabidopsis as a Model Plant. The Plant Journal,61(6), 909-921. doi:https://doi.org/10.1111/j.1365-313X.2009.04086.x

Lindsey, R. (2018, April 02). Influence of global warming on U.S. heat waves may be felt first in the West and Great Lakes regions. Retrieved from https://www.climate.gov/news-features/featured-images/influence-global-warming-us-heat-wavesmay-be-felt-first-west-and

Lopez, H., West, R., Dong, S., Goni, G., Kirtman, B., Lee, S., \& Atlas, R. (2018). Early emergence of anthropogenically forced heat waves in the western United States and Great Lakes. Nature Climate Change,8(5), 414-420. doi:10.1038/s41558-0180116-y 
Peterhansel, C., Horst, I., Niessen, M., Blume, C., Kebeish, R., Kürkcüoglu, S., \& Kreuzaler, F. (). Photorespiration. The arabidopsis book, 8, e0130. doi:10.1199/tab.0130

Pitzschke, A. (2013). From Bench to Barn: Plant Model Research and its Applications in Agriculture. Advancements in Genetic Engineering,02(02). doi:10.4172/2169-0111.1000110

Raikhel, N. V. (2001). Plant Physiology: Past, Present, and Future. Plant Physiology,125(1), 1-3. doi:10.1104/pp.125.1.1

Ryan, B. F., Ryan, T. A., Jr., \& Joiner, B. L. (1989). Minitab [Computer software]. State College, PA: Minitab.

Seed Handling. (2018, November 26). Retrieved January 7, 2019, from https://abrc.osu.edu/seed-handling

Smith, T. T., Zaitchik, B. F., \& Gohlke, J. M. (2012). Heat waves in the United States: Definitions, patterns and trends. Climatic Change,118(3-4), 811-825. doi:10.1007/s10584-012-0659-2

Social Science Statistics. (n.d.). Retrieved from https://www.socscistatistics.com/

Wiebold, W. J. (2012, July 2). None Like It Hot. Retrieved November 2, 2018, from https://ipm.missouri.edu/IPCM/2012/7/None-Like-It-Hot/

Zhu, J., Oh, E., Wang, T., \& Wang, Z. (2016). TOC1-PIF4 interaction mediates the circadian gating of thermoresponsive growth in Arabidopsis. Nature Communications, 7(1). doi:10.1038/ncomms 13692 


\section{Appendix A}

Additional Pictures of Growth Chamber Construction

See the Figures A1, A2, and A3 below for images of steps during the construction of the growth chambers within the study. The same design was used for both the control and experimental groups. Figure 1 shows the 2' by 2' by 3' PVC frame fitted together. Figure 2 shows one of the long sides of the growth chamber (2' by 3') covered in Mylar reflective insulation, and Figure 3 shows a diagonal view of the growth chamber with reflective insulation.

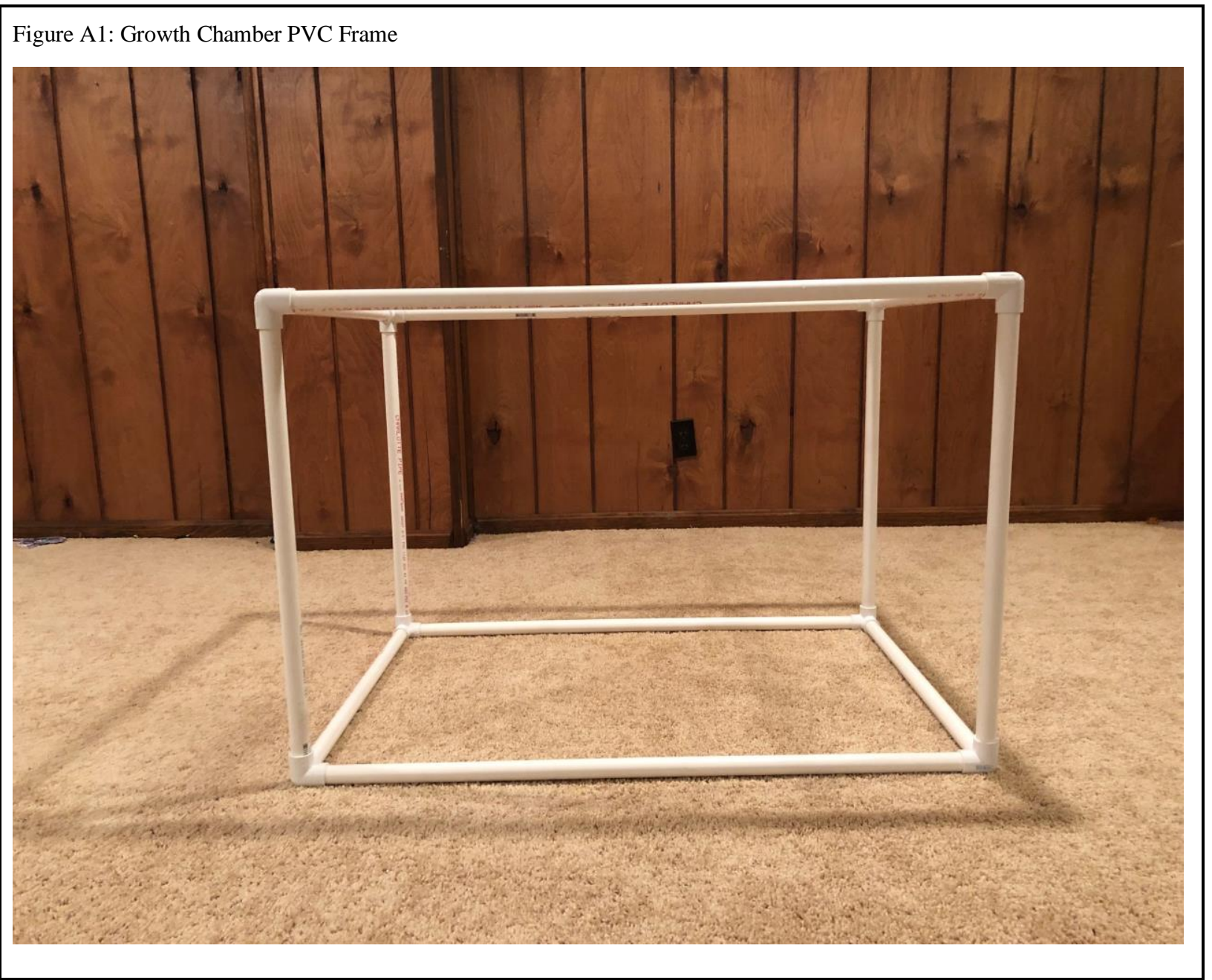




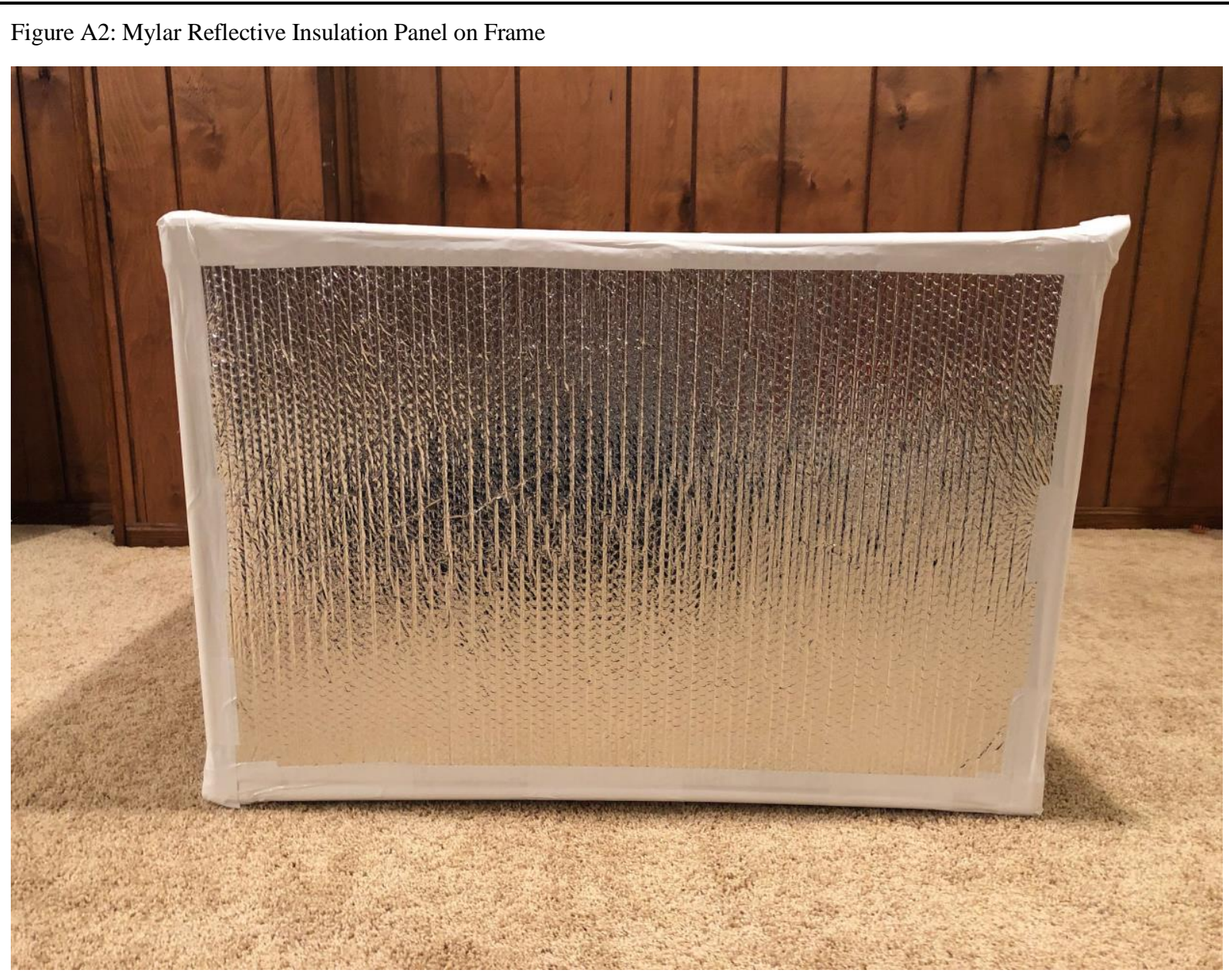


Figure A3: Diagonal View of Mylar Insulation on Growth Chamber

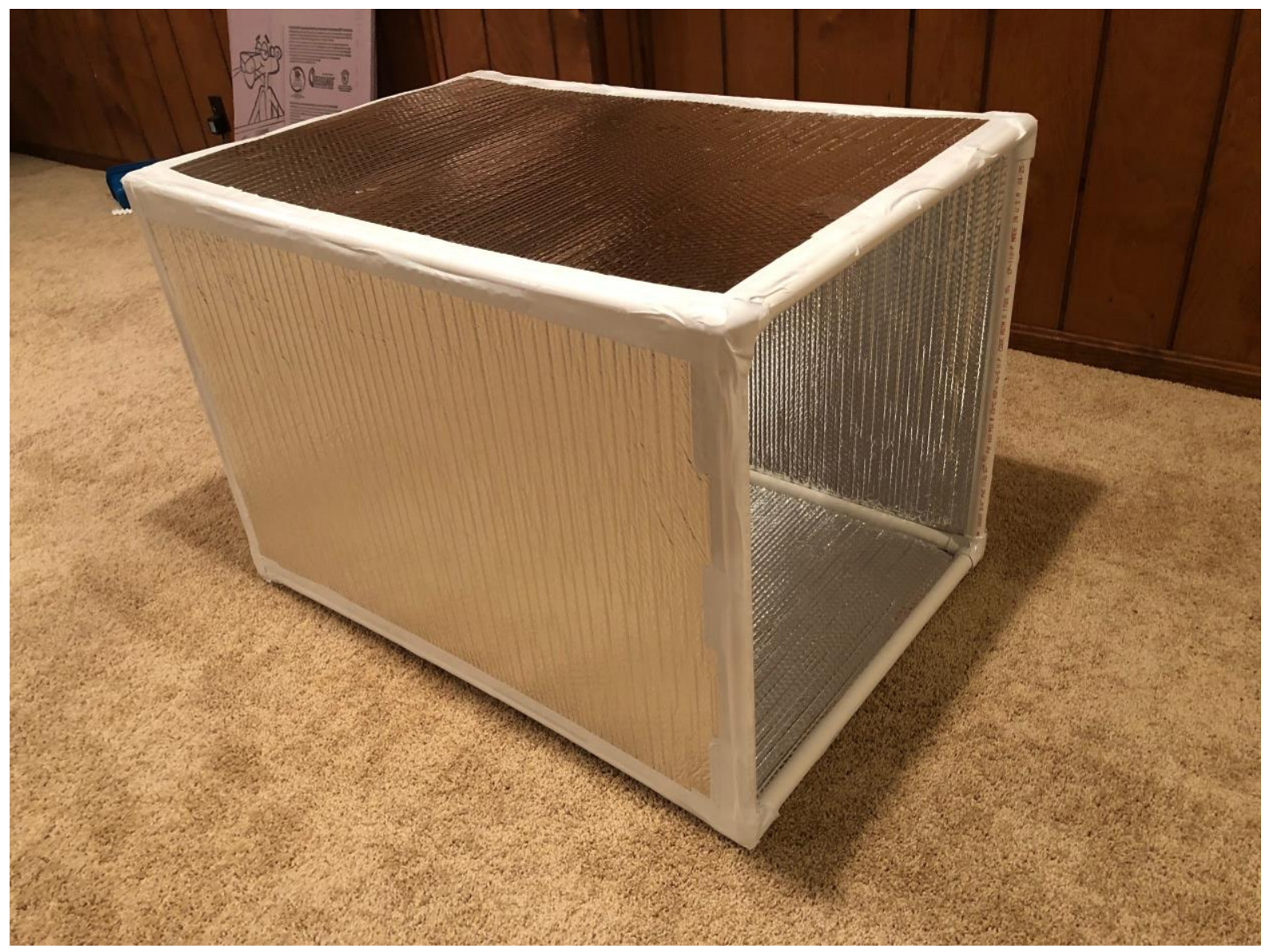




\section{Appendix B}

Raw Data from Control Group

Table B-1: Control Group Raw Data (part one)

Date after sowing

\begin{tabular}{|c|c|c|c|c|c|c|c|c|c|c|c|c|c|c|c|c|c|c|c|c|c|c|c|c|c|c|c|c|c|c|c|c|c|c|}
\hline & 1 & 1 & $\begin{array}{l}1 \\
8\end{array}$ & $\begin{array}{l}1 \\
9\end{array}$ & $\begin{array}{l}2 \\
0\end{array}$ & $\begin{array}{l}2 \\
1\end{array}$ & $\begin{array}{l}2 \\
2\end{array}$ & & $\begin{array}{l}2 \\
4\end{array}$ & $\begin{array}{l}2 \\
5\end{array}$ & 2 & $\begin{array}{l}2 \\
7\end{array}$ & $\begin{array}{l}2 \\
8\end{array}$ & $\begin{array}{l}2 \\
9\end{array}$ & 3 & $\begin{array}{l}3 \\
1\end{array}$ & $\begin{array}{l}3 \\
2\end{array}$ & $\begin{array}{l}3 \\
3\end{array}$ & $\begin{array}{l}3 \\
4\end{array}$ & $\begin{array}{l}3 \\
5\end{array}$ & $\begin{array}{l}3 \\
6\end{array}$ & $\begin{array}{l}3 \\
7\end{array}$ & $\begin{array}{l}3 \\
8\end{array}$ & $\begin{array}{l}3 \\
9\end{array}$ & 4 & $\begin{array}{l}4 \\
1\end{array}$ & $\begin{array}{l}4 \\
2\end{array}$ & 4 & $\begin{array}{l}4 \\
4\end{array}$ & $\begin{array}{l}4 \\
5\end{array}$ & 4 & $\begin{array}{l}4 \\
7\end{array}$ & $\begin{array}{l}4 \\
8\end{array}$ & $\begin{array}{l}4 \\
9\end{array}$ \\
\hline No. & & & & & & & & & & & & & & & & & & & & & & & & & & & & & & & & & & \\
\hline 1 & 2 & 2 & 2 & & & & - & & & & & & & & & & & & & & & & & & & & & & & & & & & \\
\hline 2 & 2 & 3 & 3 & & & & - & & & & & & & & & & & & & & & & & & & & & & & & & & & \\
\hline 3 & 2 & 2 & 2 & & & & - & & & & & & & & & & & & & & & & & & & & & & & & & & & \\
\hline 4 & 3 & 4 & 4 & & & & - & & & & & & & & & & & & & & & & & & & & & & & & & & & \\
\hline 5 & 2 & 2 & 2 & & & & - & & & & & & & & & & & & & & & & & & & & & & & & & & & \\
\hline 6 & 3 & 3 & 4 & & & & - & & & & & & & & & & & & & & & & & & & & & & & & & & & \\
\hline 7 & 3 & 4 & 4 & & & & - & & & & & & & & & & & & & & & & & & & & & & & & & & & \\
\hline 8 & 2 & 2 & & & & & - & & & & & & & & & & & & & & & & & & & & & & & & & & & \\
\hline 9 & 3 & 4 & 4 & 4 & & & - & & & & & & & & & & & & & & & & & & & & & & & & & & & \\
\hline 10 & 2 & 2 & 2 & & & & - & & & & & & & & & & & & & & & & & & & & & & & & & & & \\
\hline 11 & 4 & 4 & 4 & 4 & & & - & & & & & & & & & & & & & & & & & & & & & & & & & & & \\
\hline 12 & 2 & 2 & 2 & & & & - & & & & & & & & & & & & & & & & & & & & & & & & & & & \\
\hline 13 & 4 & 4 & 4 & 4 & 5 & 5 & 6 & 6 & 6 & 6 & 6 & 7 & 7 & 8 & 8 & 8 & 9 & 9 & & 9 & & 9 & 9 & 9 & 9 & 9 & 9 & 9 & 9 & 9 & 9 & 9 & & 9 \\
\hline 14 & 2 & 3 & 3 & & & & - & & & 4 & 4 & 4 & 4 & 5 & 5 & 5 & 5 & 6 & & 6 & & 7 & 8 & 8 & 8 & 8 & 8 & 8 & 8 & 8 & 8 & 9 & & 9 \\
\hline 15 & 4 & 4 & 4 & & & & - & & & & & & & & & & & & & & & & & & & & & & & & & & & \\
\hline 16 & 4 & 4 & 4 & 4 & 4 & 4 & 4 & 5 & 5 & 5 & 6 & 6 & 6 & 6 & 7 & 7 & 8 & 8 & & 8 & & 9 & 9 & 9 & 9 & 9 & 9 & 9 & 9 & 9 & 9 & 9 & & $\begin{array}{l}1 \\
0\end{array}$ \\
\hline 17 & 3 & 4 & 4 & 4 & 4 & 4 & 4 & 4 & 4 & 5 & 5 & 5 & 6 & 6 & 6 & 7 & 7 & 7 & & 8 & & 9 & 9 & 9 & $\begin{array}{l}1 \\
0\end{array}$ & $\begin{array}{l}1 \\
0\end{array}$ & $\begin{array}{l}1 \\
0\end{array}$ & $\begin{array}{l}1 \\
0\end{array}$ & $\begin{array}{l}1 \\
0\end{array}$ & $\begin{array}{l}1 \\
1\end{array}$ & $\begin{array}{l}1 \\
1\end{array}$ & 8 & & 8 \\
\hline 18 & 3 & 4 & 4 & 4 & 4 & 4 & 4 & 4 & 5 & 5 & 6 & 6 & 6 & 6 & 7 & 7 & 7 & 8 & & 9 & & 9 & 9 & $\begin{array}{l}1 \\
0\end{array}$ & $\begin{array}{l}1 \\
0\end{array}$ & $\begin{array}{l}1 \\
0\end{array}$ & $\begin{array}{l}1 \\
0\end{array}$ & $\begin{array}{l}1 \\
0\end{array}$ & $\begin{array}{l}1 \\
0\end{array}$ & $\begin{array}{l}1 \\
0\end{array}$ & $\begin{array}{l}1 \\
0\end{array}$ & $\begin{array}{l}1 \\
0\end{array}$ & & $\begin{array}{l}1 \\
0\end{array}$ \\
\hline 19 & 3 & 3 & 4 & 4 & 4 & 4 & 4 & 4 & 4 & 5 & 5 & 6 & 6 & 6 & 7 & 7 & 7 & 8 & & 9 & & 9 & 9 & 9 & $\begin{array}{l}1 \\
0\end{array}$ & $\begin{array}{l}1 \\
0\end{array}$ & $\begin{array}{l}1 \\
0\end{array}$ & $\begin{array}{l}1 \\
0\end{array}$ & $\begin{array}{l}1 \\
0\end{array}$ & $\begin{array}{l}1 \\
0\end{array}$ & $\begin{array}{l}1 \\
0\end{array}$ & $\begin{array}{l}1 \\
0\end{array}$ & & $\begin{array}{l}1 \\
0\end{array}$ \\
\hline 20 & 3 & 4 & 4 & 4 & 4 & 4 & 4 & 4 & 4 & 4 & 5 & 5 & 5 & 6 & 6 & 6 & 6 & 7 & & 8 & & 8 & 8 & 8 & 9 & 9 & 9 & $\begin{array}{l}1 \\
0\end{array}$ & $\begin{array}{l}1 \\
0\end{array}$ & $\begin{array}{l}1 \\
0\end{array}$ & $\begin{array}{l}1 \\
0\end{array}$ & 8 & & 8 \\
\hline 21 & 4 & 4 & 4 & 4 & & & - & & & & 4 & 4 & 4 & 4 & 5 & 5 & 5 & & & 5 & & 6 & 6 & 6 & 6 & & & & & & & & & \\
\hline 22 & 4 & 4 & 4 & 4 & & & - & & & & 4 & 4 & 4 & 4 & 4 & & & & & & & & & & & & & & & & & & & \\
\hline 23 & & & - & - & & & 2 & 2 & 3 & 3 & 3 & 3 & 4 & 4 & 4 & 4 & 4 & 4 & & 4 & & 5 & 6 & 7 & 8 & 8 & 8 & 8 & 8 & 9 & 9 & 9 & & $\begin{array}{l}1 \\
0\end{array}$ \\
\hline 24 & 4 & 4 & 4 & 4 & 4 & 4 & 4 & 5 & 5 & 5 & 6 & 6 & 6 & 7 & 7 & 7 & 8 & 8 & & 9 & & $\begin{array}{l}1 \\
0\end{array}$ & $\begin{array}{l}1 \\
0\end{array}$ & $\begin{array}{l}1 \\
0\end{array}$ & $\begin{array}{l}1 \\
1\end{array}$ & $\begin{array}{l}1 \\
1\end{array}$ & $\begin{array}{l}1 \\
1\end{array}$ & $\begin{array}{l}1 \\
1\end{array}$ & $\begin{array}{l}1 \\
1\end{array}$ & $\begin{array}{l}1 \\
2\end{array}$ & $\begin{array}{l}1 \\
2\end{array}$ & 9 & & 9 \\
\hline
\end{tabular}




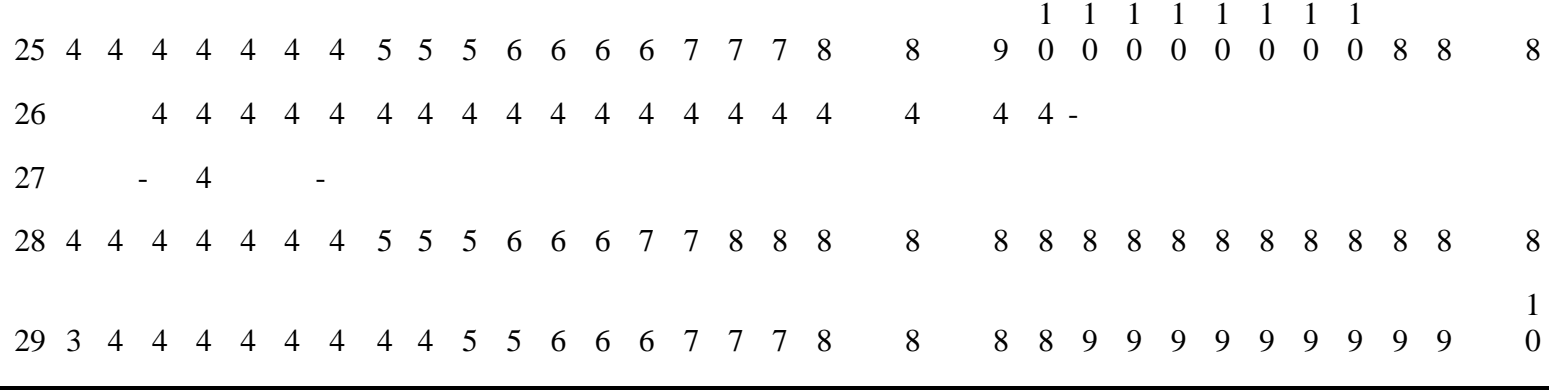

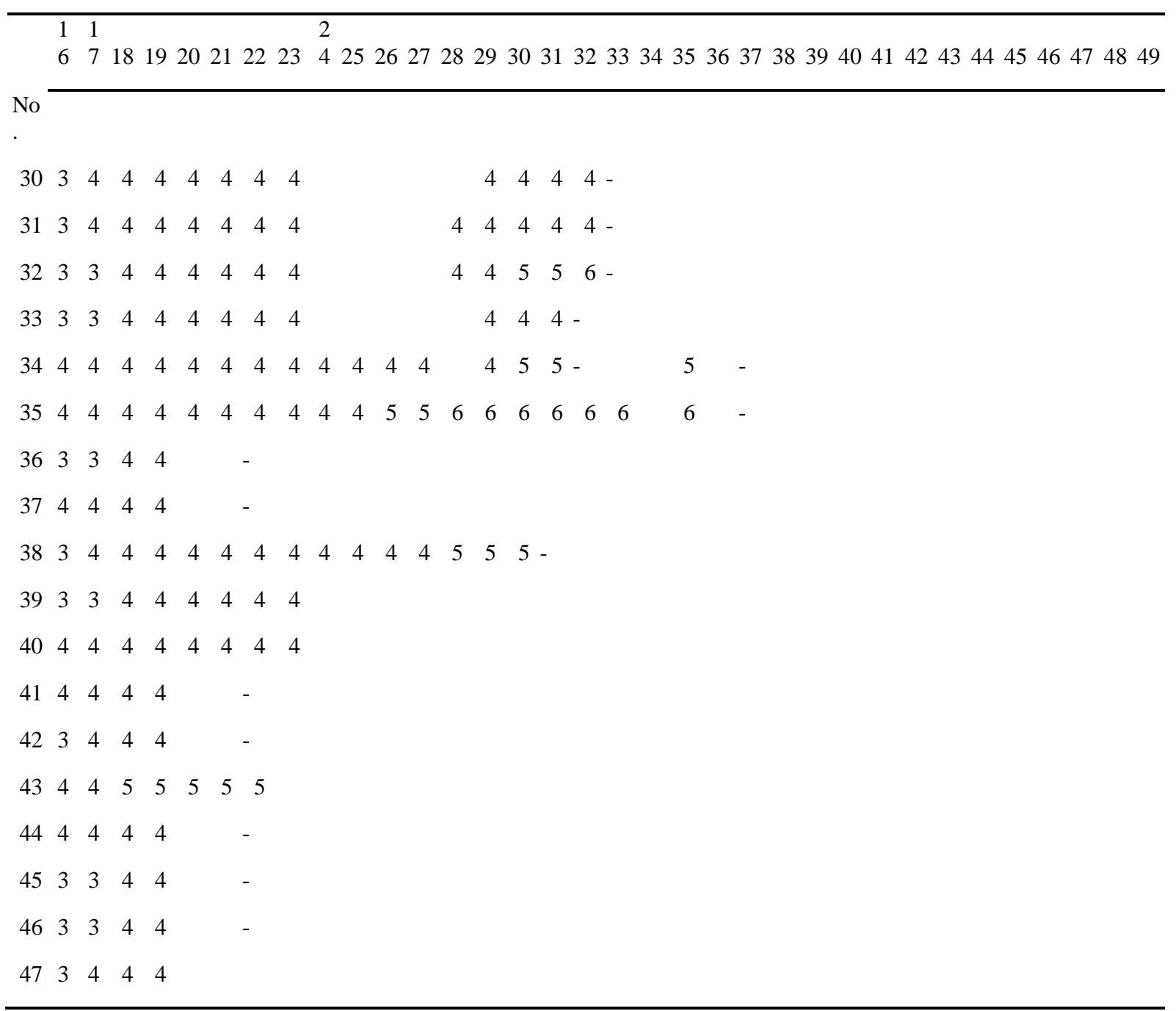




\section{Appendix C}

Raw Data from Experimental Group

Table C-1: Control Group Raw Data (part one)

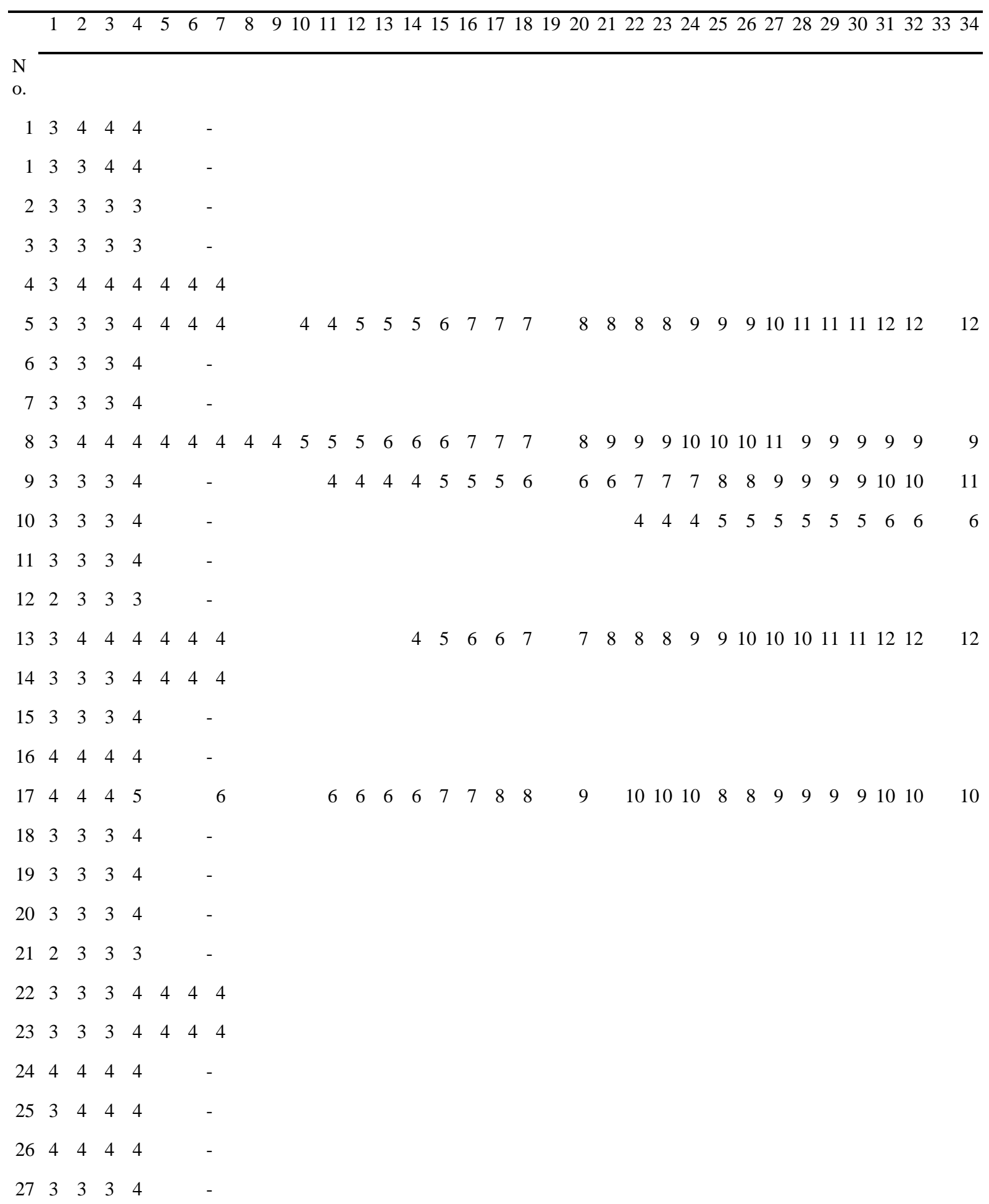


$\begin{array}{lllll}28 & 3 & 3 & 3 & 4\end{array}$

$\begin{array}{lllll}29 & 3 & 3 & 3 & 4\end{array}$

Table C-2: Control Group Raw Data (part two)

Date after transfer (into growth chambers)

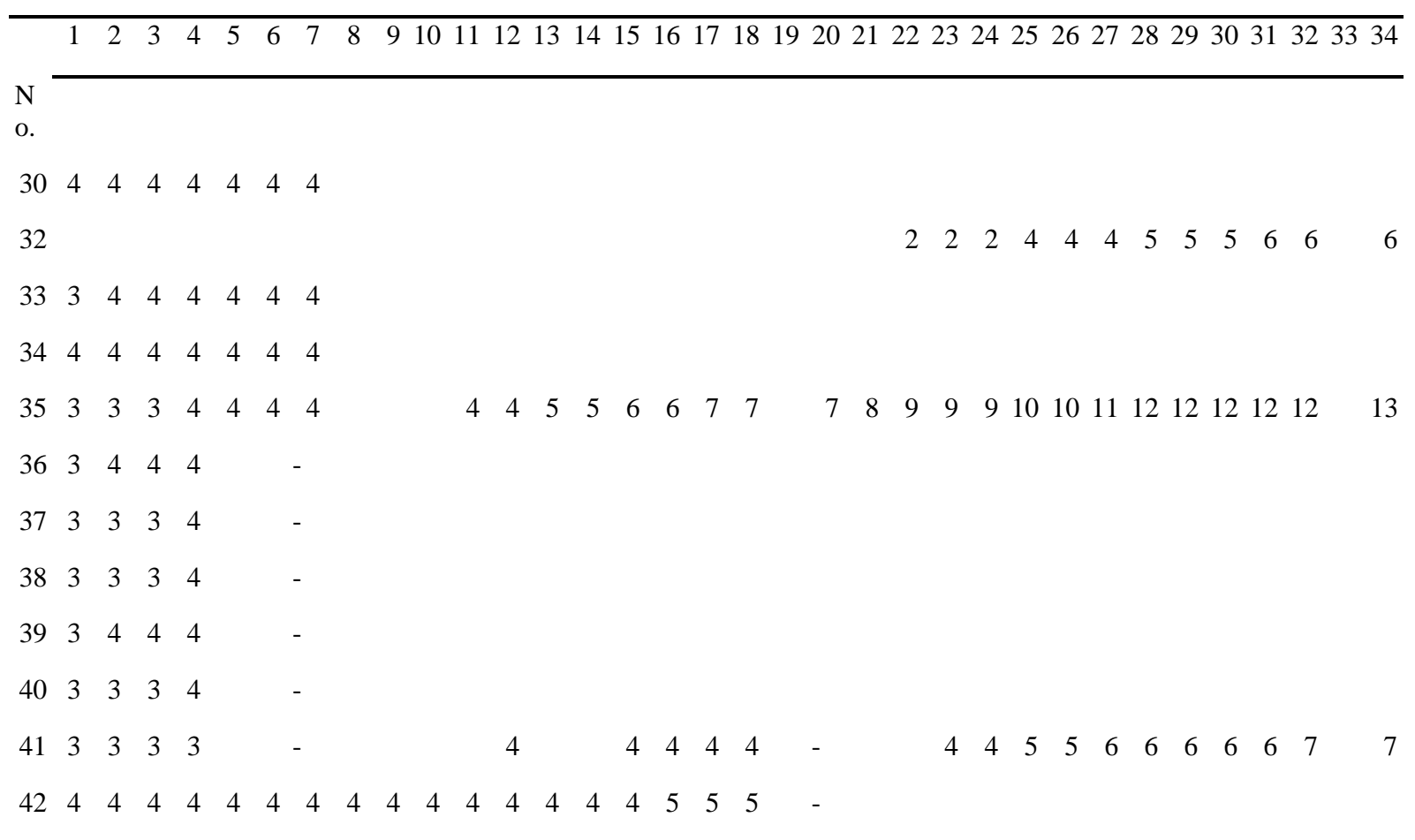

